\title{
Jornalismo televisivo e crime violento, ou sobre um decisivo "não-dito"
}

\author{
Francisco Rui Cádima
}

\section{Resumo}

Este texto pretende fazer uma reflexão sobre algo que é relativamente novo na comunicação social portuguesa, que é a sobreatenção, de características e efeitos sensacionalistas, que em particular 0 meio televisivo está a conceder - com honras de abertura de telejornal - aos delitos criminosos de grande impacto público, isto num momento em que Portugal está mergulhado em uma crise de valores e econômica tida como uma das mais profundas da era democrática. Dessa forma, procuramos contextualizar a questão, em termos teóricos, e também no contexto nacional, e discorrer sobre práticas e metodologias de enquadramento jornalístico que contribuam para superar esse tratamento de tipo tabloide, na perspectiva de que os media tenham neste âmbito sobretudo uma ação preventiva simultânea com a sua estratégia informativa.

\section{Palavras-chave:}

Jornalismo. Televisão. Violência. Prevenção. Escrutínio.

Francisco Rui Cádima | frcadima@gmail.com

Professor Associado com Agregação do Departamento de Ciências da Comunicação da FCSH - Universidade Nova de Lisboa. Áreas de Cinema e Televisão; e de Novos Media. Coordenador do Curso de Licenciatura e Membro da Comissão Executiva do mesmo DCC-FCSH-UNL.

\section{Introdução}

"Os filmes violentos aumentam a frequência das condutas agressivas - de tipo físico ou verbal nas crianças dos nove aos catorze anos"

Marcel Frydman

"0 não sentido das coisas me faz ter um sorriso de complacência. De certo tudo deve estar sendo o que é."

Clarice Lispector

0 Verão de 2008, em particular o mês de agosto, ficou marcado, em Portugal, por um crescendo de crimes a que a mídia, naturalmente, deu eco. A catadupa de incidentes, alguns de enorme gravidade, foi, inclusive, objeto de alargado debate e crítica social, sobretudo em relação ao potencial 'fator mimético' gerado pelos próprios meios de comunicação social.

Como temos defendido, a violência estereotipada na mídia não transmite violência à sociedade da forma como muitas vezes se pretende fazer crer. Acusar os media de 'principais' instigadores da violência é iludir o problema. As raízes da violência têm que ser encontradas em contextos mais complexos da sociedade, sem que isso 
impeça uma necessária análise das próprias práticas mediáticas.

Nesta comunicação pretende-se fazer uma breve reflexão sobre o papel da televisão em um contexto de midiatização do crime violento, procurando demonstrar que, enquanto instituição de socialização, criadora de vínculo social, a televisão tem inevitavelmente uma função sensível quer na interiorização coletiva do sentimento de insegurança face à violência, quer também nos mimetismos de comportamentos agressivos, pelo que a gestão da informação televisiva nesse âmbito, necessita, muito em particular nesse domínio, ser enquadrada por práticas editoriais fortemente ancoradas em um conhecimento técnico-científico específico e interdisciplinar sobre a matéria. E também perceber que, como dizia Gérard Leblanc (1987), caso 0 não faça, caso transforme 0 crime em mero fait-divers com honras de abertura de telejornal, então não está fazendo nada além de auto-legitimar tendencialmente, por omissão, o próprio governo e o partido do governo, no caso, diminuindo ou mesmo anulando o decisivo interesse público de um debate fundamental para o futuro do país e para as gerações vindouras.

\section{Principais teses e marco teórico}

A investigação nesta área é naturalmente complexa e tem fornecido ao longo das últimas décadas diferentes pontos de vista e algumas nuances aparentemente contraditórias. Se violento era Shakespeare, se violento é o real, a verdade é que a mídia hoje se aproxima cada vez mais do modelo do real, mas projetando sobretudo o seu olhar 'tátil' - que é um olhar cego - e não tanto reflexivo ou investigativo, como supõe a responsabilidade social e a deontologia da mídia, designadamente no plano das práticas jornalísticas.

Como temos defendido em diferentes artigos anteriormente publicados, a violência estereotipada na mídia não transmite violência à sociedade da forma que muitas vezes se pretende fazer crer. Acusar a mídia de "única" instiladora da violência é iludir o problema.

As raízes da violência têm, por isso, que ser encontradas em contextos mais complexos da sociedade, e, portanto, também nas próprias práticas midiáticas. Porque não há qualquer dúvida de que a mídia constrói representações e "recicla" o real com determinados impactos e repercussões sociais. E isso partindo de um princípio elementar, como recorda Miquel Rodrigo, em referência a Norbert Elias, de que tanto a natureza (o instintivo e 0 inato) como a cultura (o aprendido e o socializado) intervêm nos comportamentos violentos. Reconhece também 0 autor, no atual contexto dos estudos de mídia e face ao estado da questão das ciências da comunicação, o carácter contraditório e a falta de consenso na comunidade científica em relação aos impactos sociais da violência na televisão:

No hay, pues, acuerdo en si la violencia en televisión produce mayor violencia en los individuos 
y en la sociedad. Si bien no hay investigadores que nieguen la influencia de los medios, lo que no está claro es en qué grado la ejercen. Algunos autores apuntan que la influencia puede ser muy importante, mientras que otros discrepan en este punto. El planteamiento que hace algún autor es que, aunque la influencia sea mínima, hasta qué punto el hecho de que pueda afectar a muy pocas personas no deja de tener graves consecuencias (RODRIGO et al., 2008).

Mas é fundamental conhecer a dimensão

midiática do problema e sobretudo a evolução do seu quadro epistemológico. Não se pode também iludir que nomeadamente as imagens violentas na televisão são também potenciadoras de respostas agressivas e são, portanto, uma forma de aprendizagem de comportamentos agressivos.

Precisamente, nos anos 60, um estudo europeu dirigido por André Glucksmann (1966) defendia que uma correlação estatística entre a delinquência juvenil e as técnicas de difusão de massa seria deveras arriscada na medida em que, de acordo com os postulados sociológicos, não era aceitável estabelecer estatisticamente uma relação precisa, direta, entre a influência da televisão e os comportamentos divergentes ou desviantes dos indivíduos.

Entretanto, um dos estudos de referência dos anos 80 que integrou um importante programa de investigação sobre a violência na televisão norte-americana abordava a possível relação causal entre a exposição a atos de violência na televisão e a conduta agressiva, concluindo que esta se verificava só em jovens que estão predispostos a ser agressivos, e só em algumas circunstâncias. "Reconhece-se também que tanto 0 visionamento frequente de actos de violência como a conduta violenta ou agressiva podem ser 0 resultado conjunto de alguma outra fonte comum" (p. 145). James Halloran (1981) referia que este estudo confirmava, de certa maneira, os dados por ele obtidos em estudos realizados na Grã-Bretanha:

Este e outros estudos levaram-nos a afirmar que não se havia demonstrado suficientemente que a televisão (ou outros meios de comunicação) se possa considerar como uma causa ou sequer como um importante factor que contribua para alguma forma de conduta violenta" $\mathrm{e}$ concluía: "Isto não nos deve surpreender; 0 que nos deveria surpreender é a persistência com que os investigadores continuam à procura de relações de causa e efeito. Na realidade, em sentido estrito, não nos deveríamos perguntar qual é o efeito da televisão. Quase nunca fazemos perguntas desse tipo acerca de outras instituições como a família, a religião ou a educação (p. 145).

De acordo com Berkowitz (apud VALA et al., 2000), segundo a sua teoria sobre a agressão impulsiva ou reativa, "a agressão verifica-se com mais probabilidade quando, a um estado de disposição interna negativo, se associam, no meio externo ou interno, indícios agressivos (objctos associados à agressão)" (p. 23). Assim, por exemplo os filmes violentos funcionariam já como um desses indícios agressivos. Ainda segundo Berkowitz, os filmes agressivos podem funcionar como "ativadores" de "projetos de ação", com influência no comportamento. 
Na mesma linha, Gerbner (1989) explicava os efeitos de longo prazo da exposição à violência filmada e vários são os autores que coincidem na propensão para a assimilação de modelos de violência, sobretudo por parte de jovens desenquadrados socialmente, mesmo que esses comportamentos agressivos se venham a verificar bastante mais tarde. Para George Gerbner há outro aspecto que deverá merecer toda a atenção e que tem a ver com os efeitos de violência das imagens, quando considera que a regularidade com que estamos a contatar, por meio da televisão ou do cinema, com a imagem de um mundo ameaçador e perigoso, se repercute de forma negativa em nós próprios, na medida em que provoca ansiedade ou mesmo temor e desconfiança relativamente ao "outro".

Uma outra dimensão do problema prende-se com a possibilidade de uma exposição prolongada a imagens violentas poder induzir efeitos contraditórios: por um lado, uma maior tolerância à violência por parte dos telespectadores em geral, o que pode gerar um efeito de banalização; mas, por outro, paradoxalmente, um efeito de medo pela violência social redifundida e consequentemente a legitimação da imagem de controle da autoridade policial como resposta securitária. Vista a questão pelo lado da psicologia, ou mesmo da psicanálise, teríamos de concluir com Tisseron (2004, p. 132) que

A primeira necessidade de qualquer educação para as imagens é a de nos ensinar a proteger dos traumatismos que elas podem sempre despertar em nós, com as consequências desastrosas que evocamos. Para isso, o melhor é, evidentemente, curarmo-nos dos nossos traumatismos ocultos a fim de que deixe de haver o risco de alguma imagem poder despertar-nos monstros sem o sabermos.

É claro que os efeitos da violência das imagens serão sempre de temer. Como conta Serge Tisseron a propósito do seu livro, antes da investigação desenvolvida nesse contexto, tinha a percepção de que as imagens violentas só teriam perigos se pudessem despertar antigas "vivências ocultas", mas algo mudou na sua percepção:

Depois de a ter terminado, penso que elas são perigosas também pelo poder de intensificarem os fenómenos regressivos nos grupos. Isto pode ter consequências importantes se os grupos se cimentarem pelo recurso à acção como meio privilegiado de reduzir as tensões que nele surgem. É verdade, em contrapartida, que isso não será assim se os grupos se organizarem em torno da imitação lúdica e da simbolização verbal. Já Swift escrevia, há muito tempo, que há duas maneiras de lutar contra os piolhos nos cabelos das meninas pobres. Pode rapar-se-lhes os cabelos, mas também se pode lutar contra a pobreza. Os governos que, perante a violência televisiva, não falam senão de censura, são como os que, na história de Swift, sonhavam em mandar cortar os cabelos de todas as meninas. Continua a ser a história da tesoura (TISSERON, 2004, p. 141).

\section{Caso português: estudos}

Em Portugal há fundamentalmente dois estudos de referência sobre esse tema, ambos promovidos pela então AACS - Alta Autoridade para a Comunicação Social. Um mais próximo, embora datado do ano 2000, intitulado "Avaliação da 
violência na televisão portuguesa", e outro, anterior, de 1993, intitulado genericamente "Os portugueses e a violência nos meios de comunicação social", sendo este basicamente um "estudo de opinião" sobre a violência nos media portugueses, à altura.

0 estudo coordenado pelo professor Jorge Vala (2000) incidiu sobre a programação e a informação dos canais generalistas de 1997 e tinha por objetivo avaliar não tanto os efeitos da televisão, mas sobretudo o grau de violência da programação em geral, caracterizar a violência emitida e fazer uma comparação entre canais no que respeitava ao grau de violência e ao seu contexto. Isso tendo como objetivo final contribuir, como é dito na apresentação do estudo, para uma programação televisiva "mais responsável" e para "audiências mais ativas e críticas". E tal como se dizia na introdução ao trabalho em referência:

São muitas as pesquisas que revelam que a violência na televisão é urna fonte importante de aprendizagem de comportamentos agressivos; constitui uma forma privilegiada de difusão da normatividade desse tipo de comportamentos; contribui para urna dessensibilização à violência e às suas consequências; e facilita uma representação paranóide do mundo - um mundo em que não é possível confiar nos outros, onde a probabilidade de se ser vitimado é elevada, e onde se justifica o uso da força". Os autores do estudo reconheciam ainda não exagerar "0 papel da televisão na aprendizagem dos comportamentos agressivos ou da sua normatividade social, na dessensibilização à violência quotidiana, ou na construção do medo e do sentimento de insegurança; nem ignoramos os factores que a pesquisa tem assinalado como factores moderadores dos efeitos da difusão da violência através da televisão. Esta é apenas uma das instituições de socialização e de regulação social (VALA, 2000, p. 15).

Relativamente às conclusões então enunciadas sobre os programas de informação, procurando fazer a caracterização global da violência na informação, o estudo coordenado por Jorge Vala analisou 225 programas (total de 84 horas de programação, sendo estes programas na sua maioria noticiários). No conjunto da amostra registraram-se 785 sequências violentas, sendo que as imagens violentas (44\% das sequências violentas registradas) são sobretudo de violência física. Vala refere que nesse tipo de programação a gravidade dos atos violentos refere-se "ao grau máximo de violência observada numa sequência violenta, visual ou descrita. Verificou-se que 53\% das sequências violentas têm consequências físicas ou psicológicas graves" (p. 193).

Um outro dado interessante é verificar que, em uma hora de informação televisiva, cada espectador observava nove sequências de violência descrita ou representada em imagens, 38\% das quais incluem visualização ou referência verbal a mortes. Em termos de "densidade" (percentagem do tempo do programa ocupado com interações violentas), $6 \%$ do tempo de emissão informativa é ocupado com sequências violentas, valor idêntico ao da ficção. Mas 0 valor provavelmente mais inesperado é o relativo aos noticiários generalistas: 74\% desses blocos 
incluem pelo menos uma interação violenta, com uma densidade de $10 \%$ face ao total do bloco em causa.

Finalmente, o estudo refere que a frequência de atos violentos graves é maior nos programas informativos do que na programação recreativa ou na publicidade, e conclui:

Se se tomar em consideração apenas este indicador, poderá dizer-se que a programação recreativa e a publicidade, a terem eventuais efeitos indirectos nas audiências, tê-lo-ão sobretudo a nível da aprendizagem da agressão, enquanto que a programação informativa poderá ter mais efeitos a nível do medo ou de uma representação paranóide do mundo (VALA, 2000, p. 194).

É muito interessante comparar as conclusões desse estudo com os resultados do estudo de opinião também promovido pela Alta Autoridade para a Comunicação Social (1993) uns anos antes. Dividida a violência veiculada pelos media em três grupos tipológicos, a saber:

- «violência factual», aquela que mais se aproxima da violência «real», e que surgiu sobretudo definida como uma descrição ou divulgação de factos reais violentos

- «violência de pormenor», também com uma forte ligação à realidade, mas já com uma evidente preocupação de pormenorização do facto violento, visando claramente chocar o espectador/leitor

- «violência gratuita», já sem implicar um fundamento verídico, e que surge caracterizada como uma comunicação de violência pela violência, ou seja, sem que haja um fundamento minimamente lógico e credível que justifique os actos de violência subjacentes à acção (p. 89).
Os inquiridos, em termos da aceitação/não

aceitação da veiculação desses tipos de violência, manifestaram fundamentalmente opiniões de rejeição, quer em relação à "violência de pormenor":

- aceitação condicionada da sua veiculação, em função de horários e de pré-avisos de exibição, com 0 intuito básico de proteger segmentos mais sensíveis da população;

- rejeição da sua veiculação, só em casos pontuais, e quando se pensa que a pormenorização de factos violentos sã tem a ver com noções mórbidas e/ou sádicas (AACS, 1993, p. 90).

Quer em relação à "violência gratuita":

- aceitação da sua veiculação quando apenas interpretada como uma forma possível de entretenimento (ficção televisiva) mas devidamente contextualizada para os targets correctos

- rejeição total da sua veiculação quando, pretendendo ter uma base real, acaba por se render a interesses de cariz marcadamente comerciais em detrimento de uma estratégia de rigor (caso da informação) (AACS, 1993, p. 90).

Os inquiridos sublinharam ainda o que

consideraram ser "aspectos incorrectos" da veiculação da violência:

- a descriterização horária da transmissão de violência (no caso da televisão);

- a inexistência de pré-avisos acerca da posterior veiculação de situações (extremas) de violência (sobretudo no caso da informação televisiva);

- 0 exagero na intensidade com que se veicula determinado tema (com, pelo menos, alguma componente de violência), incentivando o gradual desinteresse ou alheamento perante ele 
- 0 pouco aprofundamento interpretativo das causas ou origens do fenómeno da violência (no caso dos meios de informação em geral)

- A proliferação de casos em que se opta pelo impacto (comercial) admitido para uma noticia em detrimento da salvaguarda da credibilidade ou do interesse público da mesma (sobretudo no caso dos meios de informação geral).

- Algum abuso na veiculação de programas (de entretenimento) excessivamente pautados por violência «gratuita» (no caso da ficção televisiva) (AACS, 1993, p. 91).

Não deixam de ser curiosas, na síntese conclusiva, as respostas à questão sobre a necessidade de um organismo ou instituição que tivesse por missão regular a veiculação de violência pela mídia. Só quando diretamente questionados sobre 0 assunto, os cidadãos inquiridos tendem a aceitar a existência de um tal organismo, mas desde que

fosse representativo dos cidadãos anónimos, isto é, não detivesse qualquer ligação às esferas de poder (político, económico, etc.)" e "funcionasse sobretudo ao nível do parecer, da pressão sobre os meios, ou seja, sem dispor de poder proibitivo a fim de não se confundir com uma nova forma de censura (AACS, 1993, p. 93).

\section{Para uma crítica do discurso e das práticas da mídia sobre a violência}

Ainda no caso português, e com referência a esse período mais intenso em matéria noticiosa do verão de 2008, após as declarações públicas do responsável pelo Gabinete Coordenador de Segurança e Criminalidade, Leonel de Carvalho, que considerou, em declarações à rádio TSF, que a midiatização dos assaltos poderia estar na origem de um eventual aumento destes crimes, fomentando "o sentimento de insegurança das pessoas", o diário Jornal de Notícias aprofundaria a questão e titulava inclusive que as "Notícias sobre assaltos não aumentam criminalidade", dizendo que "o recente crescimento do número de notícias sobre assaltos não fomenta um aumento da criminalidade defendem professores de comunicação social, embora apontem responsabilidades aos media na actual percepção de maior insegurança no país" (NOTÍCIAS, 2008).

A verdade é que a questão não é assim tão simples como foi titulado. Retirando o que atrás foi exposto no âmbito do contexto teórico, é evidente que os efeitos miméticos da mídia têm comprovadas consequências. Há, por assim dizer, efeitos miméticos da violência no curto prazo e outros que se enraízam, que têm um comportamento na longa duração e que são fundamentalmente estruturais, mais do que conjunturais. Uma outra questão remete para 0 estudo das práticas da mídia, procurando pensar de que forma a sua função social e o seu "poder" devem ser reorientados, mais do que para 0 "bilhete postal" criminal, para efeitos preventivos e dissuasores, e desde logo para prevenir o mau uso da mídia condenando-os então aos seus efeitos "multiplicadores" e amplificadores de fenômenos que a sociedade condena.

Esse tema deve, assim, começar por ser contextualizado. Os meios não falam, isto é, 
falam pouco ou falam mal, descontextualizam, dramatizam, quando enunciam o que está a acontecer. Contextos sociais, políticos e jurídicos relacionados com a criminalidade violenta não têm tido o espaço óbvio de que necessitam nos alinhamentos dos telejornais e na agenda da mídia, a saber, por exemplo, questões como: a) decadência e degradação da Escola e abandono escolar; b) desestruturação das famílias vs. crescimento e educação de jovens em risco; c) discriminação social/marginalização dos bairros sociais; d) inexistência de um sistema de prevenção e de inclusão social e/ou técnica e tecnológica para jovens em risco; etc., etc., são em regra matérias que não encontram a devida contextualização na matéria jornalística. Como diz um investigador português (BRANDÃO, 2010, p. 41), predominam nas aberturas dos telejornais "as notícias 'choque', dos acidentes e catástrofes", e as matérias que "comprovam a vertente 'espectáculo', que hoje, cresce na informação televisiva, na busca da conquista de maiores audiências". Esse pesquisador aponta, também, para que a informação televisiva se deve subtrair às tendências actuais que privilegiam quer a dramatização e a "imagemchoque", quer a forma sobre o conteúdo: "do bem de mercado e do espectáculo sobrepostos ao bem social; da encenação dos efeitos sobre a análise das suas causas; da crescente encenação da informação que tem tomado 0 lugar da sua contextualização [....]" (BRANDÃo, 2010, p. 36).
Sobre o primeiro tema referido - a Escola -, que é central nesse problema, chegou-se ao ponto, verdadeiramente paradoxal, de verificar que são os líderes políticos portugueses que se antecipam à própria mídia para constatar aquilo que é altamente perturbador e que tem um efeito muito nocivo socialmente - a degradação da escola pública na capital do país. Veja-se o discurso dos responsáveis da Câmara Municipal de Lisboa (CML), justamente em 2 de junho de 2008 (Sol online) - Manuel Salgado (arquiteto e vereador do Urbanismo da Câmara de Lisboa):

Lisboa é a cidade mais bonita do Mundo, mas tem o pior parque escolar do país [...] a recuperação do parque escolar é uma das obras prioritárias para [...] a Câmara de Lisboa e está integrada no grupo de intervenções para as quais a autarquia preparou um pedido de empréstimo do Banco Europeu de Investimento (LISBOA, 2008).

Por seu lado, António Costa (2008), Presidente da CML afirmava na altura: "Lisboa tem hoje 0 parque educativo mais degradado do país e é quase 'criminoso' que as gestões de direita da CML tenham deixado chegar as coisas a este ponto". E ainda: "O estado do parque escolar é catastrófico". Finalmente, foi o próprio José Sócrates (SÓCRATES, 2008), primeiro-ministro de Portugal a reconhecer 0 estado do parque escolar nacional: "Queremos construir escolas do nosso tempo (...) a sensação que temos é que já vamos tarde".

A mídia, sobre o tema, "não estava lá", de fato, nunca esteve verdadeiramente lá e muito tem a 
fazer para futuramente vir a "estar lá". A crise que se anuncia no sistema de mídia fala-nos de maior precariedade no setor e de perda de independência das redações, pelo que as tarefas de escrutínio da coisa pública são cada vez mais complexas e difícieis. A Educação e a Escola são "editorias" de certo modo "estranhas" aos media, e em particular à televisão. Veja-se que esse é o tema que, em regra, é menos "agendado" pelos meios e aquele que menos tempo merece dos alinhamentos dos telejornais, em particular no Serviço Público de Televisão (Radiotelevisão Portuguesa - RTP).

Não é por acaso que os temas "difíceis" para quem nos governa - como a educação, a saúde, a justiça, a cultura - são os que têm menos visibilidade nas notícias do serviço público de televisão - a RTP. Não será por acaso, de fato. 0 problema é que esses são os setores fundamentais para a cidadania, para uma mais rápida consolidação da experiência e vivência democrática que, naturalmente, só de poderá consolidar com uma outra postura do sistema de mídia e em função da intervenção cívica e desassombrada da comunicação social.

Os meios, aqui, têm de fazer a sua opção. Os veículos públicos (RTP) fazem-na claramente, mas mal, sempre muito institucionais e dependentes do sistema de governo, como se pode ver: reduzindo, por exemplo, a matéria educativa (que é absolutamente central e vital para o progresso do país) a escassas 44 horas/ano (1,9\% do total), caindo assim no assombramento do velho aparelho ideológico que não larga, por nada, a presa. Repare-se que a educação é a temática a que foi dado menos tempo pela RTP1 em 2006 e, em regra, isso acontece, salvo nos anos excepcionais, como 2008 e 2009, aquando das lutas e greves dos professores a nível nacional, contra o demasiado burocrático sistema de avaliação pretendido impor pelo governo, sem qualquer debate público ou escolar.

Ainda a este propósito, não deixam de vir à colação reportagens do serviço público sobre 0 tema em apreço, logo condenadas pelo sistema político-administrativo. Recorde-se o caso "Dá-me o telemóvel já". Na altura, a Direcção Regional de Educação do Norte - DREN, não gostou que os órgãos de Comunicação Social tivessem mostrado o vídeo sobre a disputa de um telefone celular em uma sala de aula da escola Carolina Michaelis do Porto. Vai daí participou de diversos órgãos de informação à Entidade Reguladora da Comunicação Social - ERC e ao Ministério Público, dentre os quais o Expresso. Outro caso excepcional foi o Ministério da Educação ter estado contra reportagem, aliás rara, da RTP, na qual o Ministério acusava a televisão pública de "sonegação de imagens e de informação". Em causa estava um trabalho sobre a violência nas escolas transmitida no telejornal da RTP1 de 30 de maio de 2006. A reportagem havia sido elaborada com autorização do conselho executivo e dos docentes, e as imagens de professores e alunos foram desfocadas para que os intervenientes não pudessem ser reconhecidos, 
mas desse trabalho resultava uma informação pouco abonatória para as deficientes condições disciplinares e de ensino em uma sala de aula comum, que poderia situar-se em uma qualquer escola do país. Recorde-se aqui, a propósito, o pensamento de Marcel Frydman, referido por Peraya (1994, p. 187):

Se se pode demonstrar experimentalmente que a violência provocada [...] pela televisão pode ser atenuada por uma verbalização ou pela educação através da linguagem cinematográfica (ou audiovisual, acrescentamos nós) resta agora organizar um tal tipo de prevenção na escola.

0 mesmo é dizer - partindo dos estudos de Frydman - que resta agora organizar um tal tipo de prevenção nos meios. Veja-se 0 citado caso do assalto à estação dos CTT de Nova Oeiras, em 25 de março de 2009, que foi abertura "tabloide" dos três telejornais das generalistas, e que manteve "vivos" em contínuo, dados em geral como fait-divers, sem contextualização sociológica nem interpretação especializada; veio fundamentalmente constituir-se em álibi da secundarização de algo absolutamente determinante da agenda política, que foi o debate parlamentar sobre a possível hipoteca do país e das novas gerações face à polémica política despesista de investimento público do governo em um contexto de forte endividamento nacional perante 0 estrangeiro.

No fundo, do que se trata aqui é da recorrência de uma regularidade enunciativa, transversal à informação televisiva de um modo geral, que se configura em um ciclo contínuo de séries discursivas enquadradas pelas grandes categorias da atualidade trágica, da política institucional, do desporto (futebol) e dos fait divers sociais e criminais, estratégia que no conjunto se pode definir como um interminável "não dito", desde logo sobre a pluralidade e diversidade das vozes dos cidadãos, da sua experiência, da sua identidade, do seu patrimônio social e cultural, do seu "mundo da vida", daquilo que verdadeiramente está a acontecer, como foi 0 citado caso da degradação da instituição escolar em Portugal ao longo de décadas, que foi algo claramente abandonado pela agenda da mídia.

Memória e esquecimento é, assim, uma dualidade que, em matéria de agenda midiática, raramente se visualiza no eixo da memória. São raras as vezes em que identificamos uma abordagem mais assertiva, que vá ao encontro da virtude civil dos cidadãos e da sua experiência. Hoje, é para nós evidente, por exemplo, a partir da análise da literatura científica sobre o jornalismo televisivo em Portugal, que existem regularidades, séries discursivas constantes na construção social da realidade dada a ver pela mídia, sobretudo pela televisão, quer no plano da falta de diversidade de vozes, quer no plano do pluralismo, que no estrito espaço do jornalismo politico-partidário, no contexto dos partidos do quadro parlamentar, não chega sequer a ser verdadeiramente "plural".

Para além disso, as estratégias editoriais não são inócuas, como vimos. Se, por um lado, refletem, em regra, um modelo enunciativo institucional, 
por outro, delimitam-se, autorregulam-se em um espaço de esquecimento e de "não-ditos" internalizados pelo próprio dispositivo televisivo, que nos são denunciados por esse déficit de experiência da cidadania e pela lateralidade do conhecimento sobre os processos sociais. Em síntese, institucionalização, espectáculo e atualidade trágica dominam, em regra, a hierarquização da agenda e, em consequência, formatam a celebração do consenso e do conflito como realidades fechadas sobre si próprias, como autênticos fait divers, dado que nos surgem como uma espécie de acontecimentos sem conteúdo, que comportam em si mesmos uma informação total, que contêm em si todo o seu saber sendo percebido de igual modo por todos, garantindo um dispositivo mais próximo da "verdade" e apaziguador de todas as inquietações.

\section{Referências}

AACS - ALTA AUTORIDADE PARA A COMUNICAÇÃO

SOCIAL. Os portugueses e a violência nos meios de comunicação social. Lisboa: AACS., 1993

ANTÓNIO Costa, Presidente da Câmara Municipal de Lisboa (CML), ao Unir Lisboa, Lisboa, 1 ago. 2008.

BRANDÃo, Nuno G., As Notícias nos Telejornais. Que serviço público para o século XXI?, Lisboa: Guerra e Paz, 2010.

CÁDIMA, F. Rui. Violência, pecados e vídeo. In: 0 fenômeno televisivo. Lisboa: Círculo de Leitores, 1995. p. 151-161. A criança, a televisão e a publicidade. In: Cádima, F. Rui. Estratégias e discursos da publicidade. Lisboa: Veja, 1997. p. 77-86.
Crise e crítica do sistema de media. Lisboa:

Media XXI, 2009.

GERBNER, George. Violence et terreur dans les médias. Études et documents d'information, Paris, $n$. 102, p. 3-50, 1989.

GLUCKSMANN, André. Rapport sur les recherches concernant les effets sur la jeunesse des scènes de violence au cinéma et à la télévision. Communications, Paris, n. 7, p. 74-119, 1996.

HALLORAN, James D. Television and growing up: the impact of televised violence - report to the surgeon general (United States Health Service, from the Surgeon General's scientific advisory committee on television and social behaviour). United States Department of Health, Education and Welfare, 1972.

Los medios de comunicación social: sintomas 0 causas de la violencia? In: JOXE, Alain (org,). La violencia y sus causas. Paris: Unesco, 1981.

LISBOA é a cidade mais bonita do Mundo, mas tem 0 pior parque escolar do país". Sol online, Lisboa, 2 jun. 2008. Disponível em http://sol.sapo.pt/PaginaInicial/ Sociedade/Interior.aspx?content_id=95985. Acesso em: 19 jul. 2008.

LEBLANC, Gérard. Treize heures vingt heures: le monde en suspens. Marburg : Hitzeroth, 1987.

NOTÍCIAS sobre assaltos não aumentam criminalidade, Jornal de Notícias, 2008-08-29. Disponível em: http://jn.sapo.pt/PaginaInicial/Media/ Interior.aspx?content_id=1006146. Acesso em: 7set. 2008.

PERAYA, Daniel. A propos de Marcel Frydman, télévision et violence. Recherches en Communication, Bruxelas, n. 1, p. 187-200, 1994. RODRIG0, Miquel et al. Las teorías sobre los efectos sociales de la violencia en televisión: estado de la cuestión. Verso \& reverso, São Leopoldo, n. 49, ano XXII, 2008. Disponível em: <http://www.versoereverso. 
unisinos.br/index.php?e=13\&s=1>. Acesso em:

3 maio 2010.

SÓCRATES visita escolas em obras e fica com sensação

de que chegou 'tarde', jornal Público, 3 de Setembro

de 2008.

TISSERON, Serge. As crianças e a violência nos

écrans: a influência da televisão, cinema e jogos de

computador nas crianças. Porto: Ambar, 2004.

VALA, Jorge et al. Avaliação da violência na televisão

portuguesa: Lisboa: CIIS/ISCTE, 2000. 


\section{Expediente}

A revista E-Compós é a publicação científica em formato eletrônico da Associação Nacional dos Programas de Pós-Graduação em Comunicação (Compós). Lançada em 2004, tem como principal finalidade difundir a produção acadêmica de pesquisadores da área de Comunicação, inseridos em instituições do Brasil e do exterior.
E-COMPÓS I www.e-compos.org.br I E-ISSN 1808-2599

Revista da Associação Nacional dos Programas de Pós-Graduação em Comunicação. Brasília, v.13, n.3, set./dez. 2010.

A identificação das edições, a partir de 2008 passa a ser volume anual com três números.

\section{CONSELHO EDITORIAL}

Afonso Albuquerque

Universidade Federal Fluminense, Brasil

Alberto Carlos Augusto Klein

Universidade Estadual de Londrina, Brasi

Alex Fernando Teixeira Primo

Universidade Federal do Rio Grande do Sul, Brasil

Alfredo Vizeu

Universidade Federal de Pernambuco, Brasi

Ana Carolina Damboriarena Escosteguy

Pontifícia Universidade Católica do Rio Grande do Sul, Brasil

Ana Silvia Lopes Davi Médola

Universidade Estadual Paulista, Brasil

André Luiz Martins Lemos

Universidade Federal da Bahia, Brasil

Ângela Freire Prysthon

Universidade Federal de Pernambuco, Brasil

Antônio Fausto Neto

Universidade do Vale do Rio dos Sinos, Brasil

Antonio Carlos Hohlfeldt

Pontifícia Universidade Católica do Rio Grande do Sul, Brasil

Arlindo Ribeiro Machado

Universidade de São Paulo, Brasil

César Geraldo Guimarães

Universidade Federal de Minas Gerais, Brasil

Cristiane Freitas Gutfreind

Pontifícia Universidade Católica do Rio Grande do Sul, Brasil

Denilson Lopes

Universidade Federal do Rio de Janeiro, Brasil

Eduardo Peñuela Cañizal

Universidade Paulista, Brasil

Erick Felinto de Oliveira

Universidade do Estado do Rio de Janeiro, Brasil

Francisco Menezes Martins

Universidade Tuiuti do Paraná, Brasil

Gelson Santana

Universidade Anhembi/Morumbi, Brasil

Goiamérico Felício

Hector Ospina

Universidad de Manizales, Colômbia

Herom Vargas

Universidade Municipal de São Caetano do Sul, Brasil

leda Tucherman

Universidade Federal do Rio de Janeiro, Brasil

Itania Maria Mota Gomes

Universidade Federal da Bahia, Brasil

Janice Caiafa

Universidade Federal do Rio de Janeiro, Brasil

Jeder Silveira Janotti Junior

Universidade Federal da Bahia, Brasil
Universidade Federal de Goiás, Brasil

\section{João Freire Filho}

Universidade Federal do Rio de Janeiro, Brasil

John DH Downing

University of Texas at Austin, Estados Unidos

José Luiz Aidar Prado

Pontifícia Universidade Católica de São Paulo, Brasil

José Luiz Warren Jardim Gomes Braga

Universidade do Vale do Rio dos Sinos, Brasil

Juremir Machado da Silva

Pontifícia Universidade Católica do Rio Grande do Sul, Brasil

Lorraine Leu

University of Bristol, Grã-Bretanha

Luiz Claudio Martino

Universidade de Brasília, Brasil

Maria Immacolata Vassallo de Lopes

Universidade de São Paulo, Brasil

Maria Lucia Santaella

Pontifícia Universidade Católica de São Paulo, Brasil

Mauro Pereira Porto

Tulane University, Estados Unidos

Muniz Sodre de Araujo Cabral

Universidade Federal do Rio de Janeiro, Brasil

Nilda Aparecida Jacks

Universidade Federal do Rio Grande do Sul, Brasil

Paulo Roberto Gibaldi Vaz

Universidade Federal do Rio de Janeiro, Brasil

Renato Cordeiro Gomes

Pontifícia Universidade Católica do Rio de Janeiro, Brasil

Ronaldo George Helal

Universidade do Estado do Rio de Janeiro, Brasil

Rosana de Lima Soares

Universidade de São Paulo, Brasil

Rossana Reguillo

Instituto Tecnológico y de Estudios Superiores do Occidente, México

Rousiley Celi Moreira Maia

Universidade Federal de Minas Gerais, Brasil

Samuel Paiva

Universidade Federal de São Carlos, Brasil

Sebastião Albano

Universidade Federal do Rio Grande do Norte, Brasil

Sebastião Carlos de Morais Squirra

Universidade Metodista de São Paulo, Brasil

Simone Maria Andrade Pereira de Sá

Universidade Federal Fluminense, Brasi

Suzete Venturelli

Universidade de Brasília, Brasil

Valério Cruz Brittos

Universidade do Vale do Rio dos Sinos, Brasil

Veneza Mayora Ronsini

Universidade Federal de Santa Maria, Brasil

Vera Regina Veiga França

Universidade Federal de Minas Gerais, Brasil

\section{COMISSÃO EDITORIAL}

Felipe da Costa Trotta I Universidade Federal de Pernambuco, Brasi Rose Melo Rocha I Escola Superior de Propaganda e Marketing, Brasil Adriana Braga I Pontifícia Universidade Católica do Rio de Janeiro, Brasil

\section{CONSULTORES AD HOC}

Virginia Pradelina da Silveira Fonseca I Universidade Federal do Rio Grande do Norte, Brasi Christa Liselote Berger I Universidade do Vale do Rio dos Sinos, Brasi Márcia Benetti I Universidade Federal do Rio Grande do Sul, Brasil Tattiana Gonçalves Teixeira I Universidade Federal de Santa Catarina, Brasil

Gislene da Silva I Universidade Federal de Santa Catarina, Brasil José Afonso Junior I Universidade Federal de Pernambuco, Brasil EDIÇÃO DE TEXTO E RESUMOS I Everton Cardoso

TRADUÇÕES PARA O INGLÊS I Sieni Campos, Lisa Earl Castillo e Sabrina Glendhill EDITORAÇ̃̃ ELETRÔNICA I Roka Estúdio
COMPOS I wWw.compos.org.br

Associação Nacional dos Programas de Pós-Graduação em Comunicação

Presidente

Itania Maria Mota Gomes

Universidade Federal da Bahia, Brasil

itania@ufba.br

Vice-presidente

Julio Pinto

Pontifícia Universidade Católica de Minas Gerais, Brasil juliopinto@pucminas.br

Secretária-Geral

Ana Carolina Escosteguy

Pontifícia Universidade Católica do Rio Grande do Sul, Brasil carolad@pucrs.br 